\title{
Transcatheter device closure of atrial septal defect in dextrocardia with situs inversus totalis
}

\author{
Kiran Prasad Acharya ${ }^{1}$, Chandra Mani Adhikari ${ }^{1}$, Aarjan Khanal ${ }^{2}$, Sachin Dhungel ${ }^{1}$, Amrit Bogati ${ }^{1}$, Manish \\ Shrestha ${ }^{3}$, Deewakar Sharma ${ }^{1}$
}

${ }^{1}$ Department of Cardiology, Shahid Gangalal National Heart Centre, Kathmandu, Nepal
${ }^{2}$ Department of Internal Medicine, Kathmandu Medical College, Kathmandu,Nepal
${ }^{3}$ Department of Pediatric Cardiology, Shahid Gangalal National Heart Centre, Kathmandu, Nepal

Corresponding Author: Chandra Mani Adhikari

Department of Cardiology Shahid Gangalal National Heart Centre Kathmandu, Nepal

Email: topjhap@gmail.com

Cite this article as: Acharya K P, Adhikari C M, Khanal A, et al. Transcatheter device closure of atrial septal defect in dextrocardia with situs inversus totalis. Nepalese Heart Journal 2019; Vol 16(1), 51-53

Received date: 17 th February 2019

Accepted date: 16th April 2019

Abstract

Only few cases of Device closure of atrial septal defect in dextrocardia with situs inversus totalis has been reported previously. We present a case of a 36 years old male, who had secundum type of atrial septal defect in dextrocardia with situs inversus totalis. ASD device closure was successfully done. However, we encountered few technical difficulties in this case which are discussed in this case review.

Keywords: atrial septal defect; dextrocardia; transcatheter device closure,

DOI: https://doi.org/10.3126/njh.v16i1.23901

\section{Introduction}

An atrial septal defect (ASD) is an opening in the atrial septum, excluding a patent foramen ovale. ${ }^{1}$ ASD is a common congenital heart defect, with an estimated birth prevalence of 1.6 per 1000 live births and a $97 \%$ probability of survival into adulthood. ${ }^{2}$

Dextrocardia with situs inversus totalis involves complete transposition (right to left reversal) of the thoracic and abdominal organs. The heart is not in its usual position in the left chest, but is on the right. Specifically related to the heart, this is referred to as dextrocardia. The stomach, which is normally in the left upper abdomen, is on the right. In patients with situs inversus totalis, all of the chest and abdominal organs are reversed and appear in mirror image when examined or visualized by tests such as $\mathrm{X}$-ray. Dextrocardia with situs inversus is the most common variety of dextrocardia. Situs inversus with Dextrocardia or Situs inversus totalis occurance is once in about 6-8,000 live births. ${ }^{3}$ Among a subgroup of patients with situs inversus dextrocardia with concordant AV connections, ASD is relatively rare. ${ }^{4}$

ASD can be treated either using transcatheter closure or with surgical closure. Though, both approaches are effective, transcatheter closure is associated with lower mortality, complications, and length of hospital stay while surgical closure has a lower rate of residual shunting. ${ }^{5}$
There are only two case reported of closure of secundum ASD associated in patients with dextrocardia and situs inversus totalis. A case report of total endoscopic robotic ASD repair in a patient with dextrocardia and situs inversus totalis was reported from Japan. ${ }^{6}$ A case report of successful ASD device closure in such case was reported from India. ${ }^{7}$

Our case report describe the unexpected problems encountered during the device closure of ASD secundum in dextrocardia with situs inversus totalis.

\section{Case Report}

A 36 years old male, tailor by occupation was referred from a periphery hospital to Shahid Gangalal National Heart Centre with the findings of dextrocardia on chest $\mathrm{x}$-ray and an atrial septal defect on echocardiography. He complained of chest discomfort and shortness of breath on and off for past five months. The pain was not radiating to any site, was not associated with nausea, vomiting, palpitations, diaphoresis, dizziness or loss of consciousness. He has no history of orthopnea, swelling of legs, sore throat, joint pain, weakness of limb or facial deviation. There was no history of any cardiovascular disease in his family.

A routine physical examination revealed a right-sided cardiac apex. His vitals were stable with blood pressure of 110/80 $\mathrm{mmHg}$ and regular pulse of $80 / \mathrm{min}$ with normal volume and equally palpable in both limbs. Cardiac auscultation revealed splitting of

@Nepalese Heart Journal. Nepalese Heart Journal retains copyright and work is simultaneously licensed under Creative Commons Attribution License CC - BY 4.0 that allows others to share the work with an acknowledgement of the work's authorship and initial publication in this journal. 
second heart sound at right upper sternal border. Cardiac apex was palpable on the right fifth intercostal space along the midclavicular line. Chest radiography confirmed that his heart was in the right chest and that the cardiac apex pointed to the right. The aortic arch was on his left, mediastinal contours were normal, lungs were clear; and the gastric bubble was on his right side.

His transthoracic echo findings were: abdominal situs inversus, dextrocardia Inferior venecava/superior venecava draining into left sided right atrium , pulmonary veins draining into right sided left atrium , AV/ VA concordance, great arteries relation normal, atrial septal defect secundum $1.6 \mathrm{~cm}$ in size, with shunt from left atrium to right atrium, mild tricuspid regurgitation (TR) with TRPG: $24.0 \mathrm{mmHg}$ with dilated right atrium and right ventricle and intact interventricular septum.He was further evaluated with transesophageal echocardiography(TEE) which revealed dextrocardia with atrial septal defect, $1.7 \mathrm{~cm}$ in size with left to right shut. Aortic rim was absent while all other rims were adequate. As there was a dilation of RA and RV and ASD was suitable for device closure, we opted for ASD device closure.

\section{The procedure}

Device closure procedure was done under local anesthesia assisted with transthoracic echocardiogram. The right femoral vein was cannulated, with adequate heparinization JR catheter with terumo wire was used to cross the ASD and JR was attempted to park in the pulmonary vein.

Probing the pulmonary vein during the procedure was the most challenging because of abnormal orientation compared to normal heart. With difficulty JR catheter was placed in the right upper pulmonary vein and $22 \mathrm{~mm}$ Amplatzer septal occluder could be successfully deployed and we were able to release the device in stable and safe position. Post catheterization X-Ray of the chest showed device in good position.

Echocardiography $24 \mathrm{~h}$ after the procedure showed device in good position with no residual shunt.

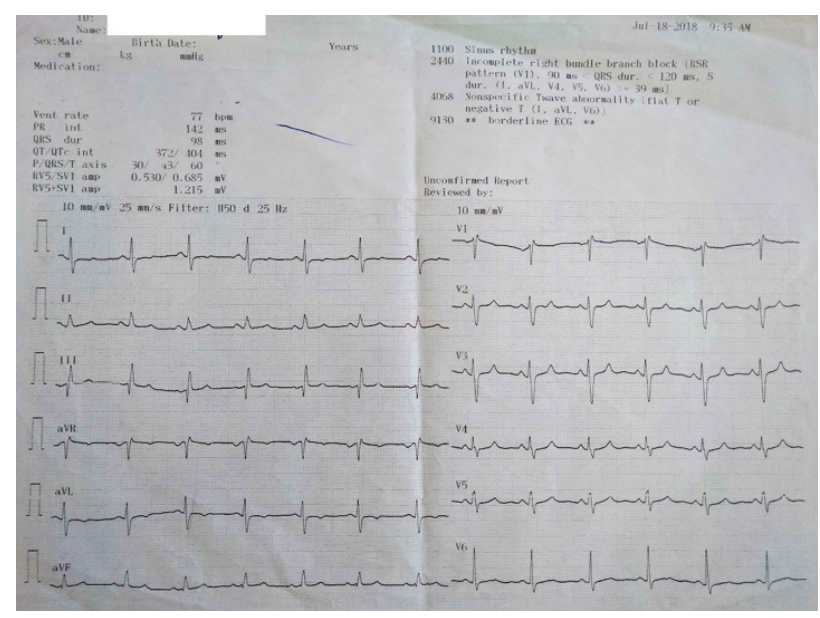

Figure 1. ECG with lead reverse

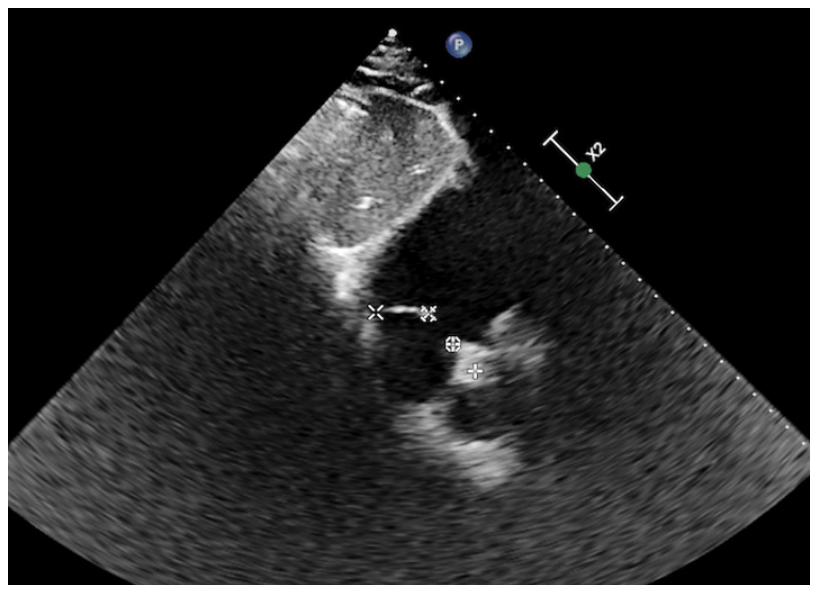

Figure 2. Transthoracic Echocardiograph Bicaval view

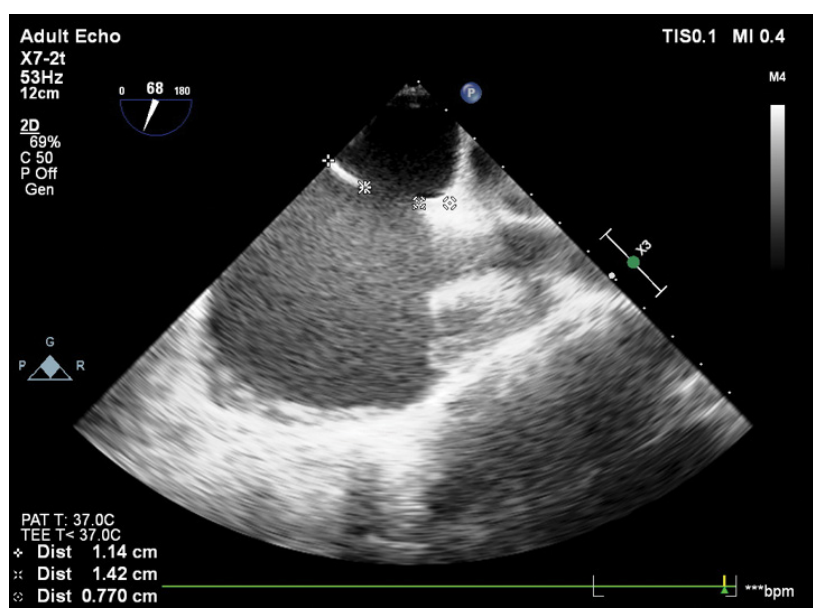

Figure 3. TEE Bicaval view

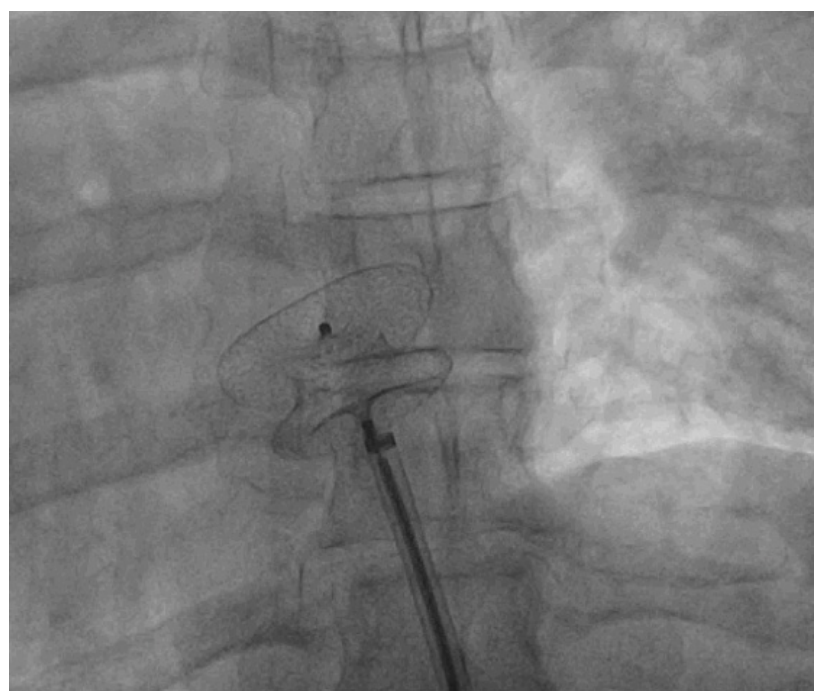

Figure 4. During device closure procedure device with cable 


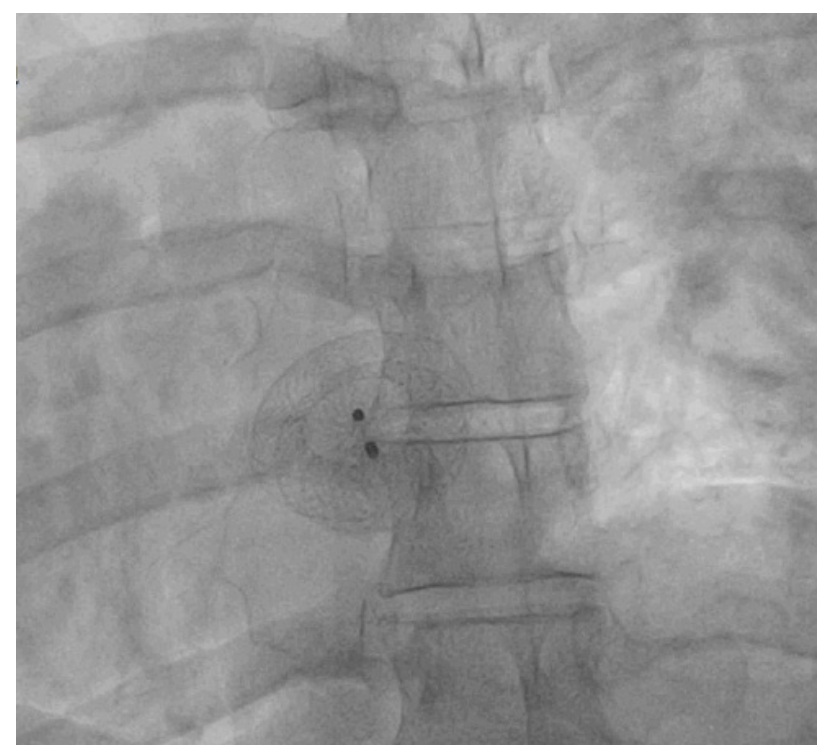

Figure 5. During Device closure procedure Device without cable

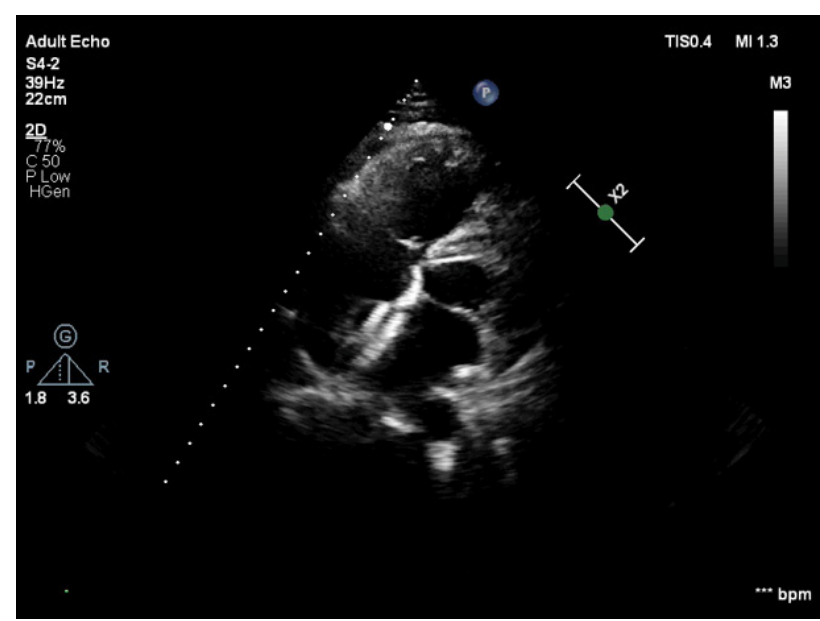

Figure 6. Post procedure echocardiography

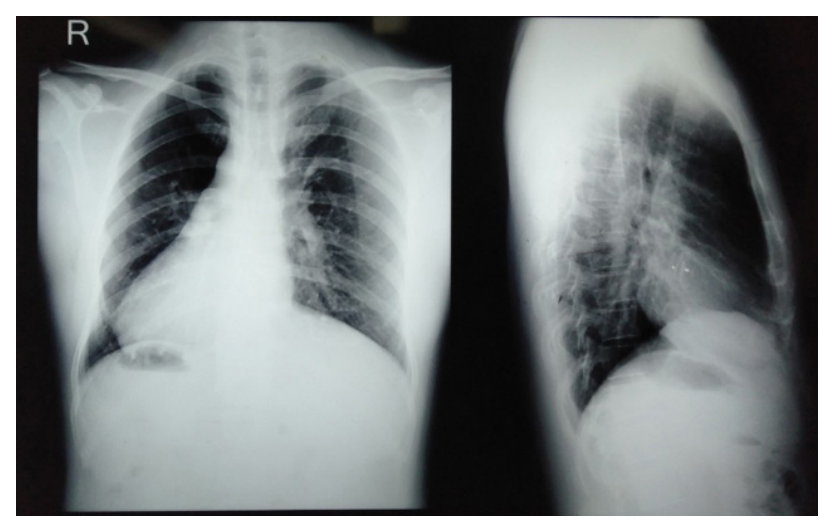

Figure 6. Post procedure echocardiography

\section{Discussion}

Transcatheter closure of secundum ASD in patients with levocardia is easily done under fluoroscopic and proper imaging. TEE imaging was difficult but the images were reversed. In dextrocardia with situs inversus totalis ASD device closure is technically difficult. Difficulty lies in placing the JR catheter in the pulmonary vein and in imaging.

The interatrial septum plane is oblique in cases of levocardia, with the left atrium more posterior than the right atrium. This relationship changes in certain conditions such as dextrocardia and scoliosis. ${ }^{8}$ In dextrocardia, the interatrial septum is directed anteriorly and to the right, with the morphologic right atrium situated to the right and slightly posteriorly, and the morphologic left atrium to the left and slightly anteriorly. ${ }^{9}$ Our case highlights the technical difficulties encountered during device closure of ASD secundum in situs solitus associated with dextrocardia. Attention should be paid to the abnormal orientation of the interatrial septum and its relationship to the right and left atria. Guidance by hand injections and pressure tracing may be more helpful than TEE.

With proper prior planning, device closure should be considered for closure of ASD secundum in dextrocardia with situs inversus totalis patients.

\section{Conclusion}

Our case highlights the technical difficulties encountered during device closure of ASD secundum in dextrocardia with situs inversus totalis. ASD device closure in dextrocardia with situs inversus totalis can be done. Abnormal orientation of the inter atrial septum should be taken care with the proper use of imaging modalities like echocardiography during the procedure.

\section{References}

1. DJ D.Fundamentals of Pediatric cardiology.Lippincott Williams \& Wilkins;2006.73-8 p.

2. Van der Linde D, Konings EEM, Slager MA, et al.Birth Prevalence of congenital heart disease worldwide: a systemic review and meta-analysis.J Am Coll Cardiol 2011;58(21):2241-7.

https://doi.org/10.1016/j.jacc.2011.08.025

3. Supriya, S.Saritha, Seema Madan. Situs Inversus Totalis - A Case Report. IOSR Journal of Applied Physics (IOSR-JAP) 2013 ;3(6):12-16. https://doi.org/10.9790/4961-0361216

4. Garg N, Agarwal BL, Modi N, et al. Dextrocardia: an analysis of cardiac structures in 125 patients. Int J Cardiol 2003; 88:143-55.

https://doi.org/10.1016/S0167-5273(02)00539-9

5. Villablanca PA, Briston DA, Rodes-Cabau J, et al. Treatment options for the closure of secundum atrial septal defects.A systemic review and meta-analysis.Int J Cardiol.2017;241:149-55.

https://doi.org/10.1016/j.ijcard.2017.03.073

6. Kenji Iino, Go Watanabe, Norihiko Ishikawa, et al. Total endoscopic robotic atrial septal defect repair in a patient with dextrocardia and situs inversus totalis Interactive CardioVascular and Thoracic Surgery 2012;14;476-8. https://doi.org/10.1093/icvts/ivr103

7. BS Vimal Raj, Oommen K George, Sunil T Chandy. Transcatheter closure of multiple artial septal defects in situs inversus with dextrocardia. Indian heart journal 2008; 60:152-154.

8. Ho SY, Mccarthy KP and Faletra FF. Anatomy of left atrium for interventional echocardiography. Eur J Echocardiogr 2011; 12: i11-i15.

https://doi.org/10.1093/ejechocard/jer093

9. Lev M, Liberthson RR, Eckner FA, et al. Pathologic anatomy of dextrocardia and its clinical implications.Circulation 1968; 37: 975-999.

https://doi.org/10.1161/01.CIR.37.6.979 